\title{
Inserção de gênero no currículo de história e a formação para o trabalho docente
}

\author{
Maria Aparecida Souza Couto* \\ Maria Helena Santana Cruz**
}

\section{Resumo}

Inserir o olhar de gênero na condução da disciplina História do curso de Pedagogia numa instituição de ensino superior objetivou a despertar no alunado a percepção de que a história é construída por homens e mulheres indistintamente de orientação sexual, etnia, religião ou classe social, desenvolvendo a noção de que o gênero é a construção histórica e social sobre corpos sexuados. O relato de experiência como docente busca contribuir para a formação de educadoras/es capazes de identificar no currículo a ausência do gênero, e o necessário enfrentamento dessa lacuna. A metodologia adotada é nutrida de referencial bibliográfico e análise dos relatos coletados, por meio de questionário, cujas questões abertas aplicadas a 43 estudantes do quinto período permitiram que os progressos fossem manifestados e os desafios desvendados, revelando que as alunas encaram a docência para além das determinações do gênero, embora haja resquícios da tradição que liga a educação ao cuidado e ao afeto, marcas indeléveis da naturalização do feminino.

Palavras-chave: Ensino de História. Gênero. Trabalho.

\footnotetext{
* Graduada em Serviço Social (UCSAl); Licenciada em Educação Física (UFS); Mestrado e Doutorado em Educação (UFS); Professora da Faculdade Amadeus; técnica na Secretaria de Estado da Educação de Sergipe (SEED). Área de interesse: formação de professore/as; Gênero e Violência. E-mail: cidabasc@hotmail.com

* Professora Emérita da Universidade Federal de Sergipe; Pós-doutorado, Doutora em Educação (UFBA); Professora do Programa de Pós-graduação em Educação e Serviço Social da UFS. Coordenadora da REDOR - Rede Feminista Norte-Nordeste de Estudos e Pesquisas Interdisciplinares sobre a Mulher e Relações de Gênero (biênio 2016-2018). E-mail: helenacruz@uol.com.br
} 


\section{Gender insert in the history curriculum and the training for teaching work}

\section{Abstract}

Inserting the gender perspective in the conduct of the discipline History in an institution of higher education of the Pedagogy course, aimed to awaken in the student the perception that history is constructed by men and women regardless of sexual orientation, ethnicity, religion or social class, developing the notion that gender is the construction historical and sexual by bodies. The report of experience as a teacher seeks to contribute to the formation of educators capable of identifying in the curriculum the absence of gender, and the need to confront this gap. The methodology adopted is based on bibliographical references and reports collected through a questionnaire, whose open questions applied to 43 students of the fifth period, allowed the progress to be made manifest and the challenges uncovered, revealing that female students face teaching beyond the gender determinations, although there remains the tradition that links education to care and to affection, indelible marks of the naturalization of the feminine.

Keywords: Job. Gender. Teaching History.

\section{Inserción de género en el curriculo de historia y la formación para el trabajo docente}

\section{Resumen}

Insertar la mirada de género en la conducción de la disciplina Historia del curso de Pedagogía en una institución de enseñanza superior objetivó a despertar en el alumnado la percepción de que la historia es construida por hombres y mujeres indistintamente de orientación sexual, etnia, religión o clase social, desarrollando la noción de que el género es la construcción histórico y social sobre cuerpos sexuados. El relato de experiencia como docente tiene por objetivo contribuir para la formación de educadoras / es capaces de identificar en el currículo la ausencia del género, y el necesario enfrentamiento de esa laguna. La metodología adoptada es nutrida de referencial bibliográfico y análisis de los relatos recogidos, a través de cuestionario, cuyas cuestiones abiertas aplicadas a 43 estudiantes del quinto grado permitieron que los progresos fueran manifestados $y$ los desafíos desvelados, revelando que las alumnas encaran la docencia más allá de las determinaciones del género, aunque hay restos de la tradición que une la educación al cuidado y al afecto, marcas indelebles de la naturalización de lo femenino.

Palabras-clave: Enseñanza de Historia. Género. Trabajo. 


\section{Introdução}

Compreender em quais contextos se forjam os indivíduos na sociedade contemporânea e os papéis que eles exercem em seus mais variados contextos é tema fundamental para as reflexões relacionadas à Educação. A pós-graduação em Educação, de modo geral, nos instrumentalizou para lidar com o objeto específico ao qual nos dedicamos a pesquisar durante quatro anos no doutorado, porém não nos forneceu elementos concretos para tanto, a exemplo da capacitação em gênero, os conhecimentos/familiaridade como a diversidade de gênero (classe /raça/ /idade/ geração, orientação sexual) etc., essenciais para enfrentar as demandas e os imprevistos da sala de aula local em que o currículo real se manifesta com toda a sua força.

É nessa perspectiva que as experiências por mim vivenciadas, na condição de professora da disciplina "Fundamentos e Metodologias do Ensino de História do Brasil e de Sergipe", em uma turma do curso de Pedagogia numa instituição de ensino superior da rede privada localizada na cidade de Aracaju (SE), na qual apliquei a pesquisa de campo são aqui apresentadas. Ao aceitar a vaga ansiava pela experiência à frente de uma disciplina na condição de responsável pelo traçado metodológico, bem como pela escolha do referencial teórico de suporte ao conteúdo previamente definido na ementa. Entretanto, preparar professoras e professores para ministrarem a disciplina História para alunas/os do ensino fundamental menor (do $1^{\circ}$ ao $5^{\circ}$ ano), se constituiu um desafio (uma vez que, embora parte do rol de disciplinas estudadas no mestrado e no doutorado, a área de formação na academia não esteve voltada para a pesquisa histórica). Os conteúdos da ementa da disciplina História (que apresenta os conteúdos a serem tradicionalmente trabalhados) abordam os seguintes temas:

O significado da História, fontes históricas e o homem como sujeito histórico. A relevância da História para os Anos Iniciais do Ensino Fundamental e a influência das correntes historiográficas. O ensino de História de acordo com os PCNs. Diretrizes Curriculares. História do Brasil e de Sergipe: estruturação de conteúdos, material e procedimentos didáticos. Sistemáticas de avaliação do ensino de História. Análise de situações da prática docente de História. (FACULDADE AMADEUS, 2011).

Observamos que o sujeito histórico a ser desvendado é colocado em uma perspectiva androcêntrica, destituindo a mulher como sujeito que também constrói a história.

No androcentrismo, o "homem" é uma naturalização do patriarcalismo, é como se fosse o ser humano em sua totalidade, tão superior que é confundido - ou convertido - com a soma de todos os gêneros. A tendência quase universal de se reduzir a raça humana ao termo "o homem" é um exemplo excludente que ilustra um comportamento androcêntrico, intimamente ligado à noção de patriarcado, porém não se refere apenas ao privilégio dos homens, mas também da forma como as experiências masculinas são consideradas como as experiências de todos os seres humanos e tidas como uma norma universal tanto para homens quanto para mulheres, sem dar o reconhecimento completo e igualitário à sabedoria e experiência feminina. O seu oposto, relacionando-o com a mulher, para utilização posterior dos resultados como válidos para a generalidade dos indivíduos homens e mulheres designa-se por ginocentrismo.

É importante destacar que o paradigma do conhecimento cientifico é concebido como uma 'supermasculinização' do conhecimento racional. Conforme Cruz (2014), o feminismo não apenas tem produzido uma crítica contundente ao modo dominante de produção do conhecimento científico, ao caráter androcêntrico da ciência, como também propõe um modo alternativo de operação e articulação nesta esfera. A desconstrução dos discursos e da história oficial representa uma forma de resistência buscada por meio de linhas subterrâneas, para significar uma aproximação da história de mulheres e homens e para rever processos de exclusão na história oficial. Isto porque, um conhecimento que despreza a contribuição das mulheres não é apenas um conhecimento limitado e parcial, mas um conhecimento que mantém um caráter de exclusão. É um conhecimento que reduz o outro a si mesmo, que nem sequer coloca a questão da contribuição dos diferentes como importante. 
Como alternativa pedagógica para despertar a "consciência no alunado" de que a história é construída por sujeitos, homens e mulheres, foi introduzida a abordagem crítica sobre a diversidade de "gênero e educação", como uma construção social e histórica de corpos sexuados, o que vem juntamente com as questões de classe, étnico-racial, idade/ geração, orientação sexual e religião. Esta construção social adquire contornos específicos de acordo com o momento histórico que se vive, segundo o que ensina Scott (1995).

Ao assim proceder, buscamos destacar o papel das muIheres e minorias sexuais na construção histórica da sociedade brasileira e, em particular, de Sergipe. A análise da ementa supracitada sinaliza a primeira questão importante a ser desnudada junto ao alunado - qual seja a de que não apenas os homens, mas também as mulheres, são sujeitos históricos, capazes de escrever a história cotidiana na condição de produtores e produtos das relações sociais desencadeadoras dos fatos, atitudes, crenças, representações e significados que constrói a história local, nacional e global.

Para atingir o objetivo preconizado, procedemos a uma pesquisa bibliográfica, a qual, na concepção de Gil (2002), é feita através de leitura, constituída principalmente de livros, artigos, periódicos, relatórios e notícias publicadas na imprensa. Esta pesquisa foi realizada através de uma abordagem qualitativa a qual tem por objetivo traduzir e expressar os fenômenos do mundo social, reduzindo as distâncias entre indicador e indicado, entre teoria e dados, entre contexto e ação. Como instrumento de pesquisa foi utilizada a entrevista não-estruturada, por ser considerada mais flexível, cuja principal característica é a liberdade que o entrevistador tem para desenvolver cada situação em qualquer direção que considere adequada. A amostra utilizada foi composta de 43 alunos/as do curso de Pedagogia de uma faculdade particular, em Aracaju, da qual sou docente.

\section{Descortinando caminhos: aula de História no ensino superior}

Na dinâmica desenvolvida nas aulas, de imediato, percebemos o estranhamento da abordagem sobre a construção das diferenças de gênero, entre o alunado egresso da educação básica orientado por uma formação restrita da história, contada/ensinada apenas no sentido de como decorar datas, fatos e personagens, meramente ligados ao passado, aos acontecimentos históricos sem relação com fatos da contemporaneidade. Como não é possível estabelecer datas para transformações, permanências e mudanças, defendemos que "[...] acima de tudo uma aula de história não deveria apresentar dados acabados, mas evidenciar em algum momento, o processo de construção da verdade histórica e trabalhar com a dúvida, dado comum a todas as ciências" (KARNAL, 2015).

As mudanças nem sempre são compreendidas e vistas como desejáveis e viáveis pelo professorado. Certamente, em muitos casos, a ausência de recursos e de apoio, a formação precária, bem como as desfavoráveis condições de trabalho constituem fortes obstáculos para que as preocupações com a cultura e com a pluralidade cultural, presentes hoje em muitas propostas curriculares oficiais (alternativas ou não) venham a se materializar no cotidiano escolar. O que parece ser minimamente desejável, sob a ótica de Bauman (1998, p.122) ao se falar em educação "para a diversidade", "na diversidade" e "pela diversidade" é justamente a transformação da relação pedagógica e da construção partilhada do conhecimento. Nesse sentido, tendo como base o texto "Gênero" (PYNSKY, 2010), esse modo de olhar a História foi adotado desde as primeiras aulas e ao longo do semestre, até o momento privilegiado em formato de Seminário versando explicitamente sobre a inserção do conceito e do olhar de gênero nas aulas da disciplina História. Durante o percurso do semestre houve o cuidado em trabalhar paulatinamente o novo conceito, atentando a que:

O importante não é o aluno aprender a palavra gênero com um novo sentido, mas entender e saber usar o conceito corretamente. Utilizar a palavra não é errado, mas também não é fundamental. $O$ importante é fornecer aos estudantes elementos para "um olhar de gênero", ou seja, fazer com que eles percebam como o masculino e o feminino têm sido e ainda são representados e, a partir disso, como as sociedades se organizam com base nessas representações. Estamos falando das questões de gênero. (PINSKY, 2010, p. 29). 
Desde sempre criadas como apêndices dos homens, as mulheres têm sido submetidas aos desígnios e ordens masculinas, operando uma história que as marca e reproduz relações patriarcais de poder, por vezes, alimentada pelas próprias mulheres que as sofrem. Melhor dizendo, a cultura na qual as mulheres são criadas numa conformação cultural historicamente masculina as habitua a adotar, de maneira explícita ou velada, o papel de submissa na relação com os homens, notadamente pais, irmãos e companheiros afetivos, cultura esta alimentada na família e solidificada no espaço público. Assim sendo, em consonância com Saffiotti (1987), a herança patriarcal designa, ainda hoje, nova roupagem, com o poder nas mãos, corpos e mentes masculinas, destinando às mulheres o mero papel de espectadoras, de submissas à lei do macho.

Segundo Cruz (2005), o patriarcado entre as feministas não é, em absoluto, entendido de uma maneira única. Com base no conceito de patriarcado de Max Weber, o movimento feminista muniu-se de múltiplos significados do conceito. Para Kate Millet (1970), por exemplo, o patriarcado como instituição é uma constante social que perpassa todas as formas políticas, sociais ou econômicas, embora reconheça existirem diferenças históricas e geográficas. Para esta autora, a supremacia do macho e a tradição que a perpetua por meio dos papeis sexuais atribuídos a cada um dos sexos, permanece delineando os modos de ser e de viver em sociedade.

A realidade histórica transmitida de geração a geração sofre com as convenções e relações de poder que operam recortes nos conteúdos a serem ensinados, seja no livro didático seja no currículo escolar. O próprio Plano Nacional de Educação (PNE) aprovado em 2014, responsável por definir metas para o período de dez anos do Ensino Básico ao Superior, buscou lutar contra a discriminação ao promover a equidade de gênero e difundir propostas pedagógicas sobre sexualidade (BRASIL, 2014).

No que diz respeito ao cotidiano escolar, convém salientar que os elementos discriminadores afetam diferentes dimensões: o projeto político-pedagógico, o currículo explicito e oculto, a dinâmica relacional, as atividades de sala de aula, o material didático, as comemorações e festas, a avaliação e a forma de lidar com a disciplina, a linguagem oral e escrita (piadas, apelidos, os provérbios populares, etc.), os comportamentos não-verbais (olhares, gestos, etc.) e os jogos e brincadeiras. Nesta linha de reflexão, de acordo com Silva (1996), é essencial questionar as relações de poder, as hierarquias sociais opressivas e os processos de subalternização ou de exclusão, que as concepções curriculares e as rotinas escolares tendem a preservar.

Ao elencar os conteúdos a serem explorados na disciplina ao longo do semestre, adotamos a perspectiva defendida por Silva (2007), segundo a qual o currículo não é elemento neutro de disseminação de ideias e conceitos, ao contrário, na condição de artefato norteador do ensino, pois está imerso em relações de poder uma vez que se trata de um campo contestado onde a questão "o quê ensinar" é muito mais importante do que "como ensinar", desde que, ao estabelecer critérios de escolha dos conteúdos para a redação de programas e planos de ensino, estamos exercendo o poder de levar ao estudante determinado conhecimento em detrimento de outros.

Para Pacheco (2005), inserir gênero como categoria de análise no currículo da disciplina História passa pela compreensão adicional de que existe uma dificuldade conceitual sobre o significado de currículo (e de gênero), amparada na sua complexidade e ambiguidade, o que torna a tarefa árdua, problemática e conflitual. Este nos alerta sobre a recente emergência do campo de estudos sobre currículo como um dos complicadores que afetam a sua conceituação, impedindo um acordo sobre o que realmente significa. Assim, questões tais como: o currículo deve propor o que se deve ensinar ou aquilo que os alunos devem aprender? O currículo é algo especificado, delimitado e acabado que logo se aplica ou é de igual modo algo aberto que se delimita no próprio processo de aplicação?

Pacheco (2005) ainda esclarece que currículo é também uma forma concreta de olhar para o conhecimento e para as aprendizagens construídas no contexto duma 
organização de formação. Portanto, responder ao que é currículo implica a identificação dos contextos, atores, interação e intenção de ensino. Variáveis estas que se integram e dialogam entre si, buscando revelar as características, nuances e especificidades do público peculiar ao qual se destina.

Notamos que nos conceitos de currículo até aqui apresentados está implícito que este representa a organização de conhecimento em sentido universal e supostamente neutro, ou seja, destituído do olhar sobre as diferentes identidades que povoam o ambiente escolar e, muito menos, contempla o gênero, compreendido como a construção social da diferença sexual, ou seja, as diferenças inscritas nos corpos sexuados ainda não são contempladas na grade curricular de muitas escolas e cursos de formação de professores. As identidades ainda aparecem com o caráter de fixidez e imobilismo, delegando ao âmbito da "natureza" a distinção segundo a qual à genitália do homem correspondem características masculinas e à genitália da mulher as características que definem o feminino, negando-se toda e qualquer inversão, ou seja, homem com características femininas e muIheres com características masculinas. Isto para não falar na orientação sexual de rapazes e moças que, conforme destacado por Couto (2013), são alvos de críticas, estranhamentos, repúdio e preconceitos em pleno século XXI. De modo geral, na escola impera o olhar segmentado e dividido em papéis a serem executados rigidamente por homens e mulheres de maneiras distintas e desiguais.

Nessa perspectiva, o conhecimento tematizado permanece naturalizando as diferenças e, em geral, tem como referência o homem, branco, heterossexual de origem europeia. Com relação às revoluções do nosso tempo, a centralidade da cultura na sociedade contemporânea permite questionar as estratégias pedagógicas para lidar com a pluralidade cultural e apresenta pontos a serem incluídos na formação de professoras/es multiculturalmente orientadas/os. Nesse ponto, em consonância com Hall (1997), insistimos na necessidade de uma orientação multicultural, nas escolas e nos currículos, que se assente na tensão dinâmica e complexa entre políticas da igualdade e políticas da diferença. Por conseguinte, concorda- -se que a diversidade cultural estrutura a representação de pessoas com diferentes identidades grupais que têm significações culturais diversas em um sistema social.

Apoiando-nos em Santos (2001, 2003), insistimos na necessidade de uma orientação multicultural, nas escolas e nos currículos, que se assente na tensão dinâmica e complexa entre políticas da igualdade e políticas da diferença. "As versões emancipatórias do multiculturalismo baseiam-se no reconhecimento da diferença e do direito à diferença e da coexistência ou construção de uma vida em comum além de diferenças de vários tipos" (SANTOS, 2003, p. 33). Nesta linha de reflexão, Louro (2010), defende que são os processos culturais que definem o que é ou não "natural". Para a autora, somos seres sociais que, por meio de processos culturais, produzimos e transformamos a natureza e a biologia, tornando-as históricas; e, assim, os corpos ganham sentido socialmente, isto porque:

\begin{abstract}
A inscrição dos gêneros - feminino ou masculino - nos corpos é feita, sempre, no contexto de uma determinada cultura e, portanto, com as marcas dessa cultura. As possibilidades da sexualidade - das formas de expressar os desejos e prazeres - também são sempre socialmente estabelecidas e codificadas. As identidades de gênero e sexuais são, portanto, compostas e definidas por relações sociais, elas são moldadas pelas redes de poder de uma sociedade. (LOURO, 2010, p. 11).
\end{abstract}

As teorias feministas de gênero trouxeram a discussão para o campo da cultura, para que se pudesse constatar a naturalziaçao da diferença sexual, a partir da célenbre frase de Simone de Beauvoir "não se nasce mulher", e no contexto do pós-guerra quando a mulher passou a ser vista como sujeito coletivo, histórico, ou seja, sujeito da própria história. Sendo assim, gênero é um conceito desenvolvido para contestar a naturalização da diferença sexual em várias arenas de lutas. Para Scott (1995), gênero é uma categoria de análise sociológica e histórica que permite compreender as relações sociais que estabelecem saberes para a diferença sexual, isto é, saberes que dão significados às diferenças corporais e que implicam uma organização social a partir delas. $\mathrm{O}$ uso do conceito 
de gênero permite abandonar a explicação da natureza como a responsável pela grande diferença existente entre os comportamentos e lugares ocupados por homens e mulheres na sociedade.

Essa diferença historicamente, assevera Cruz (2005), tem privilegiado os homens, na medida em que a sociedade não tem oferecido as mesmas oportunidades de inserção social e exercício de cidadania a homens e mulheres. Estes saberes não são absolutos, mas sim relativos para cada cultura. O termo vem do movimento feminista, que, ao tratar de relações de gênero, necessariamente, trata das concepções e práticas sociais que acentuam ou enfatizam o poder masculino sobre as mulheres e, mais amplamente, na sociedade; o acesso diferenciado dos dois gêneros aos recursos naturais, culturais e simbólicos, tanto para mulheres como para homens

Já a pesquisadora Judith Butler (2015), acredita que teorias de gênero, assim como sexo (que está apenas no campo biológico, mas, de acordo com Butler, poderia vir para o campo da cultura), aprisionam os corpos em uma normatividade heterossexual que não abrange a diversidade existente. Diante desse panorama, buscamos atuar na prática docente a partir da experiência de vida da turma do quinto período do curso de Pedagogia, para a organização do ensino, como uma das perspectivas adotadas na elaboração de um currículo da disciplina que fizesse algum sentido para as estudantes.

Nesta linha de reflexão, ao elencar os conteúdos a serem ministrados na disciplina "Fundamentos e Metodologias do Ensino de História" objetivamos a apresentar conteúdos próximos à realidade vivida por alunas e alunos frequentadores de curso de graduação no ensino noturno. O público é majoritariamente formado por mulheres que assumem o duplo papel de trabalhadoras no espaço público e privado, muitas delas mães. Portanto, população cuja energia vital é sugada do seu corpo desde a madrugada até altas horas da noite, mulheres que, ao chegarem a casa, de volta da faculdade, nem sempre encontram o carinho e o aconchego do lar. Ao contrário, a realidade que as espera está longe de ser colorida: preparar as roupas e as refeições dos demais membros da família além da higiene da casa se constituem em tarefas prioritárias a serem desenvolvidas diariamente e, muitas vezes, antes de irem dormir. Isto quando o sono não é retardado de modo a atender ao desejo unilateral do parceiro quando, o que essas mulheres, exaustas da lida diária, mais desejam, realmente, é fechar os olhos e dormir.

Ao assim proceder, percebemos que:

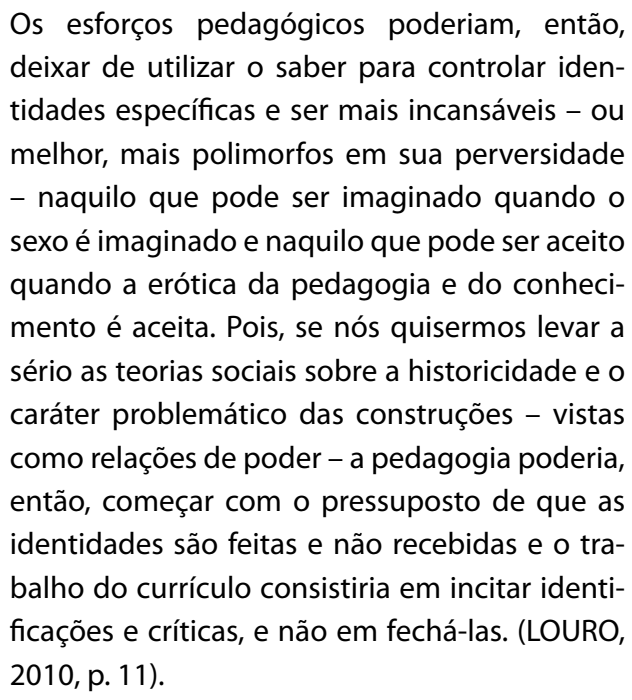

Aproximar o conteúdo do currículo da realidade vivenciada pelas alunas e alunos representou ganho qualitativo nas aulas na medida em que as pessoas se viam representadas na elaboração de micro aulas, nos textos, seminários e debates promovidos nos procedimentos metodológicos.

\section{Gênero nas aulas de História: conhecimento para a vida}

Este item é dedicado à transcrição de parte das entrevistas realizadas com os/as alunos/as da disciplina "Fundamentos e Metodologias do Ensino de História". Os/as entrevistados/as serão indicados somente pela inicial do nome, com a finalidade de manter o sigilo prometido, e a idade, pois acreditamos ser esta variável um importante indicador do pensamento de cada geração

Elegemos a turma do quinto período do curso de Pedagogia para realizar a inserção de gênero como conteúdo do currículo por entendermos que, após o impacto 
inicial representado pelo ingresso numa faculdade e as demandas específicas que a vida acadêmica impõe, os sujeitos tendem a realizar reflexões mais aprofundadas sobre o significado da qualificação para o trabalho e na formação das subjetividades, as repercussões emocionais, bem como financeiras de tal escolha.

$\mathrm{Na}$ turma composta por 43 pessoas apenas duas delas são do sexo masculino; há que se destacar a atitude esquiva adotada pelos dois respondentes ao se manifestarem de modo sucinto nas questões abertas apresentadas no questionário que foi utilizado na coleta dos dados. A faixa etária revela $40 \%$ sujeitos entre 20 e 29 anos; $30 \%$ dos sujeitos com idade entre 30 e 39 anos de idade, $28 \%$ entre 40 e 49 anos e $2 \%$ com mais de 50 anos. Observamos que a faixa etária predominante é aquela entre jovens de 20 a 29 anos, porém não há predominância entre aquelas com mais de 30 anos de idade o que pode demonstrar o potencial atrativo que o curso de Pedagogia tem para as mulheres com idade supostamente fora do perfil universitário. Reiterando pesquisas que apontam este como um curso feminino, a amostra avaliada apresenta um universo cuja maioria absoluta é composta de mulheres - 95,35\%, levando a concluir que, para as mulheres, esta é uma carreira profissional acessível e até mesmo ainda próxima do estereótipo historicamente imputado às atribuições do trabalho das professoras como extensão da formação proporcionada pelas mães no espaço doméstico.

Com relação à idade das mulheres (entre 20 a 56 anos), algumas delas afastaram-se dos estudos por períodos que variaram entre um a 21 anos. Os atributos de gênero justificam o motivo e barreiras na construção de suas trajetórias, projetos pessoais e profissionais, conforme se depreende do depoimento de M.C. (43 anos): "Casei cedo e meu esposo não permitia"; "casei cedo, fui criar os filhos"; "fui mãe muito cedo", "criação dos filhos", "faltou estímulo para continuar, somente quando minha filha completou dez anos, voltei a estudar porque eu deixava tomando conta do irmão menor". A constituição de uma família seguida da dupla jornada de trabalho expõe o desafio enfrentado pelas mulheres na alteração da divisão sexual do trabalho, questionam a luta feminista por am- pliação dos direitos ainda distante das relações de gênero mais igualitárias em todas as classes sociais.

De acordo com Cruz (2005), os elementos patriarcais com base nos estereótipos de papéis diferenciados, desvantajosos para as mulheres continuam estruturando hierarquias, proibições e divisões, conforme expresso nos relatos de proibições, por parte dos homens, ao progresso educacional das mulheres, revelados nos depoimentos de V. G. (42 anos, 16 deles fora da sala de aula) e de J. (43 anos, dez fora da sala de aula): "meu pai não queria que eu levasse meus estudos adiante". Percebemos que a construção do indivíduo na sociedade é marcada por códigos, regras sentimentos, relações, cosmovisão, que nos identificam enquanto pessoas presente em um dado grupo social. É importante salientar que a estrutura patriarcal isolou as conquistas e lutas políticas das mulheres que são, de modo geral, omitidas do registro histórico e ocupam pouco espaço nas consciências de homens e mulheres.

Escolher o curso de Pedagogia como meio de ampliar o conhecimento e conseguir independência intelectual e financeira passa a ser um importante passo para as muIheres, repercutindo, conforme assevera Dubar (2012), no processo de construção e de reconhecimento de si. Adotar a identidade docente não é algo que ocorre de imediato. Embora muitas alunas ingressem no curso de Pedagogia já com alguma experiência prática em escolas, é o contato com o conhecimento teórico expresso nas teorias pedagógicas, legislação específica, metodologias e estratégias de ensino que irão contribuir para a construção da identidade profissional e pessoal. Portanto,

[...] não se trata fundamentalmente de acumulação de conhecimentos, e sim de incorporação de uma definição de si e de uma projeção no futuro, envolvendo, antes de tudo, o compartilhamento de uma cultura do trabalho profissional e a exigência do trabalho bem feito. (DUBAR, 2012, p. 357).

Destacamos que, embora esteja havendo um aumento na escolarização entre as mulheres no Brasil, estas ainda recorrem à formação em nível superior nos cursos 
historicamente destinados às mulheres sendo o curso de Pedagogia um dos que mais abrigam mulheres. Este fato foi constatado pela UNESCO (2004), ao revelar que dentre os professores brasileiros, $81,3 \%$ são mulheres e $18,6 \%$ são homens.

Os relatos nos mostram que a formação para o trabalho e o reconhecimento de si as fortalece como pessoas capazes de enfrentar desafios e conquistar espaço na sociedade por meio do conhecimento e do trabalho. Por se tratar de um serviço útil a outras pessoas, podemos dizer que a graduação em Pedagogia inscreve-se no rol das ocupações chamadas de "ofícios", "vocações" ou "profissões", aquelas que, conforme Dubar (2012, p. 354), "não se reduzem à troca econômica de um gasto de energia por um salário, mas possuem uma dimensão simbólica em termos de realização de si e de reconhecimento social [...]", desde quando dão sentido à existência individual e organizam a vida de coletivos.

Ao escolher a graduação em Pedagogia, as alunas revelaram em seus depoimentos a necessidade de realização de investimento pessoal no processo de construção profissional de modo a obter conhecimento capaz de oferecer respaldo à prática docente. Nesse processo resta claro que o "reconhecimento de si" ocorrerá paulatinamente à ação profissional, sendo que o conhecimento adquirido ao longo da realização do curso operará mudanças significativas não somente no fazer pedagógico, mas na formação humana das alunas, agindo como catalisador do que Dubar (2012) denomina "construção de si" por meio do trabalho. Ou seja, essas pessoas passam a ser identificadas pela execução do seu trabalho e por ele reconhecidas. Assim, o trabalho docente aparece como categoria definidora da identidade social e pessoal, revelador da existência e do reconhecimento social necessário à afirmação profissional e pessoal.

Na condição de produtor de ocupação benéfica a outros, a/o pedagoga/o atua como formadora/or de pessoas em variadas instituições, nesse processo sofre mudanças em suas identidades pois o seu trabalho é considerado:

Fontes de identidades profissionais, essas atividades possibilitam mudar de empregos ao longo da vida, ao mesmo tempo garantindo uma continuidade de trajetória. É por e em um processo específico de socialização, ligando educação, trabalho e carreira, que essas identidades se constroem no interior de instituições e de coletivos que organizam as interações e asseguram o reconhecimento de seus membros como "profissionais" (DUBAR, 2010, p. 354 apud DUBAR, 2012).

Para as mulheres, as mudanças nas relações de trabalho que vêm ocorrendo nas organizações são particularmente bem-vindas, pois distanciar as ocupações do espaço privado e dos papéis historicamente imputados às mulheres como pacientes, cuidadoras e formadora dos filhos e filhas as mantêm atreladas às profissões que têm essa conotação impedindo-as de ambicionar espaços de trabalhos nas áreas técnicas. Tolhidas que são pela baixa estima culturalmente cultivada que as coloca em posições hierarquicamente inferiores quando da escoIha das profissões, partem para ocupações com menor valorização e visibilidade social, movimento colaborador da estratificação profissional entre homens e mulheres tendendo a reservar para esses espaços e lugares de desenvolvimento profissional marcados pela pouca projeção social. Com relação ao êxito das corporações de profissionais, Dubar (2012) adverte que na divisão social do trabalho permanecem as hierarquias, assim como se perpetuam as discriminações de sexo, gênero e etnia

Mudanças nas relações de trabalho implicam alterações nas subjetividades e identidades dos sujeitos, portanto, regulamentar significa operar mudanças no presente e no futuro de maneira pois,

Libertar o trabalho de suas correntes continua sendo um objetivo para manhã. Fazer com que essa libertação, fundada em regulações eficazes, seja acompanhada de desempenhos coletivos e de satisfações individuais é uma tarefa estimulante à qual todos os militantes deveriam se dedicar. Para que, enfim, todos possam construir para si uma identidade pessoal positiva em uma atividade que lhe dê prazer e que lhe permita ganhar a vida de outra maneira que não apenas pelo "suor do rosto" ou pela "punição divina". (DUBAR, 2012, p. 366). 
A abordagem do conteúdo gênero ocorreu de duas maneiras: (primeiro) ao longo das aulas de maneira indireta no enfoque dos conteúdos indicados na ementa, ao se fazer referência aos inúmeros sujeitos que compuseram e compõem a História, e que esse conhecimento não se restringia a um único ser: o homem. De maneira incisiva trabalhou-se o texto "Gênero" de autoria de Pinsky (2010), oportunidade na qual o formato de Seminário permitiu o debate e a livre exposição de ideias e pontos de vista sobre a temática em foco. Durante o percurso das aulas, buscou-se defender que "[...] a concepção de História é que deve ser mudada, repensada. $O$ recorte que o professor faz é uma opção política" (ABREU; GONTIJO e SOIHET, 2009, p. 9).

Registramos que um dos alunos manteve postura agressiva e contrária ao protagonismo feminino destacando que as mulheres são responsáveis pela forma como o mundo as trata. Esse posicionamento foi motivo de acirrado debate na turma. Já o outro aluno adotou postura aberta ao diálogo e ao novo aprendizado proporcionado pelo conteúdo trabalhado na aula de História cujo foco revelou que reiteradamente as mulheres estiveram ausentes dos relatos históricos, da condição de partícipes da construção da história e viveram (ou ainda vivem?0 sob a égide de uma sociedade masculina. Eis um dos motivos pelos quais é importante trabalhar-se com o conteúdo gênero nos cursos de formação para o trabalho docente:

Gênero trata da construção social da diferença sexual. Quando adotamos a perspectiva de gênero, estamos pensando nas maneiras como as sociedades entendem, por exemplo, "o que é ser homem"e "ser mulher", e o que é que consideram "masculino" e "feminino". Tratamos essas noções como conceitos históricos. (PINSKY, p. 31).

Portanto, gênero é um conceito datado, traz em si concepções desenvolvidas em determinada sociedade, em determinada época, e vem sendo alterado ao longo do tempo por meio do movimento inerente aos sujeitos que constroem e movem a história, ou seja, tem historicidade. As concepções produzidas, reproduzidas, consolidadas ou não podem alterar-se em cada contexto social, envolvidas pelas variáveis de classe, etnia, religião, tendo nas relações hierarquicamente desiguais a marca do poder que coloca em lugares estanques homens e mulheres desde que gênero é a construção social operada em meio às relações sociais que instituem e consolidam diferenças com base no sexo de nascimento das pessoas. Para as alunas, conforme as declarações a seguir, esse conteúdo é

\begin{abstract}
Importante para entender as diferenças estabelecidas entre homens e mulheres ao longo do tempo e entender a sociedade atual, são conteúdos muito importantes para o currículo de História, de forma que possamos entender que independente do gênero todos temos os mesmos direitos (R. C. 21anos).
\end{abstract}

Ajuda a abordar o assunto em sala de aula pensando numa construção social mais igualitária, sem distinção de direitos por ser homem ou ser mulher; ajuda a mostrar que a distinção pode ser uma forma de preconceito pois não deve haver distinção: mulher pode sim e faz muitas coisas. (R. T. 26 anos);

Nos mostra a ampliação do conhecimento crítico sobre a História, de como o gênero tem relações com a família, raça, status social, educação e como isso ainda interfere nos dias atuais (Y. 23 anos).

Uma das principais funções das aulas de história é "[...] capacitar os estudantes para perceber a historicidade de concepções, mentalidades, práticas e formas de relações sociais" (PINSKY, 2010, p. 32). Desse modo:

Ao observar que as ideias a respeito do que é "ser homem" e ser "mulher", os papeis considerados femininos e os masculinos ou a condição das mulheres, por exemplo, foram se transformando ao longo da história (como e por que), os alunos passam a ter uma visão mais crítica de suas próprias concepções, bem como das regras sociais e verdades apresentadas como absolutas e definitivas no que diz respeito às relações de gênero (PINSKY, 2010, p. 32).

Neste sentido, quando questionadas sobre a relevância do conteúdo gênero nas aulas de História as respostas foram surpreendentemente claras e diretas, como nos depoimentos a seguir: 
Interessante, pois até então não tinha a visão de que esse assunto caberia em História, só que eu vi que tem tudo a ver, pois o gênero já vem desde sempre. Importante para que possamos aprofundar sobre esse tema gênero, importante para nosso próprio status, além de trazer cultura, é útil para nos mostrar o quanto precisamos aprender para ensinar melhor (V. G. 42 anos).

Contribuiu para que eu possa entender o significado da palavra gênero, que ela não apenas distingue homem de mulher, mas sim envolve um contexto social maior, isso contribui para que o currículo amplie os conteúdos de ensino (E.R. 26 anos).

Ao falar de gênero só pensamos no masculino e no feminino, não vemos as consequências dessa divisão, as aulas foram úteis para nos alertar; me surpreendi com os temas abordados nessa disciplina (C. 36 anos).

A riqueza dos depoimentos nos mostra a potencialidade existente em trazer para o currículo gênero como conteúdo basilar na disciplina História:

Importante para mostrar que não influi o que a sociedade acha ou formula quanto ao gênero, sei que sou capaz e sei que qualquer gênero pode ser capaz de realizar qualquer tipo de trabalho (V. G. 42 anos).

Conteúdo bom, por poder contribuir sobre como os alunos veem as transformações da sociedade, o quanto tanto homens como mulheres podem desempenhar bem atividades que antes eram restritas e como eles podem passar a se enxergarem como sujeitos construtores da história sendo vários e quebrando os paradigmas existentes (A. N. 34 anos).

A abordagem do conteúdo gênero representou para as alunas, além de possibilidade real de ampliação do conhecimento para seus alunos e alunas, um desvendamento da sua condição humana pertencente ao gênero feminino, levando-as a refletir sobre a condição das mulheres e o reconhecimento de si como sujeito capaz de operar realizações e mudanças na própria vida e na vida de outras pessoas. Vide as declarações a seguir:
Conteúdo essencial para levar o professor a perceber a diferença de personalidade de cada aluno ou aluna. Entender o modo de pensamento de cada ser, independentemente de ser homem ou mulher, feminino ou masculino. Ensinar nas disciplinas para entender melhor o que é gênero, estudar meu gênero, mulher, feminina que tem pensamento próprio, ter certeza de que sou inteligente e capaz de atuar em sala de aula (S. 39 anos).

Importante para os alunos compreenderem que gênero não tem a ver apenas com sexualidade, com o sexo que nasce, vai além disso. Importante conhecer as questões feministas, as lutas das muIheres para conquistar seu espaço por igualdade profissional, social, enfim seu lugar na sociedade. (V. S. 40 anos).

Tem tudo a ver abordar gênero nas aulas de História, pois no curso de Pedagogia existem várias gerações que precisam entender qual é o seu papel no mundo e como isso é construído. (V. M. 47 anos).

Compreendi muito as definições sobre gênero que até então não sabia, desconhecia. Como um todo entendi o papel do homem e da mulher na sociedade (M. C. 43 anos).

Para mim foi muito interessante porque levantou muitas questões e o debate na sala fez com que as opiniões fossem discutidas mostrando que tanto no contexto da sociedade como no nosso dia a dia, na nossa própria vida essas questões são muito presentes; contribuiu de maneira geral principalmente quando analisei a minha construção social e percebi como nós mulheres somos tratadas na sociedade. (A. 34 anos).

O sentimento despertado nas alunas é corroborado por Pinsky (2010, p. 48): "[...] a preocupação com gênero está ajudando a reescrever a história". Indo além de acrescentar as mulheres nos livros de história, a própria História passa a ser repensada, analisada e questionada em termos de temas, de narrativas e de enfoques, situando as mulheres em seu contexto social, levando-as a refletir sobre a própria construção social que as tornou o que hoje são.

Diante deste contexto há que se atentar que: 
As concepções de gênero tanto são produto das relações sociais quanto produzem e atuam na construção destas relações, determinando experiências, influindo nas condutas e práticas e estruturando expectativas. Um "olhar de gênero" não só procura o que há de cultural nas percepções das diferenças sexuais como também a influência das ideias criadas a partir destas percepções na constituição das relações sociais em geral. (PINSKY, 2010, p. 32).

Conhecer a amplitude do olhar de gênero permite às discentes compreender que a história é construída pelas pessoas, com ideias e fatos, experiências vivenciadas por homens e mulheres (de distintas idades, sexo, classe social, etnia, religião e orientação sexual) em meio às condições materiais de vida; estas, por sua vez, interferem na constituição do pensamento, das subjetividades e representações, dos sentidos e significados construídos, ou seja, em meio às inúmeras relações travadas entre os seres humanos passam a perceber que as relações de gênero ocupam lugar fundante das demais relações sociais desde quando define lugares, espaços e tempos baseados na assimetria entre os sexos.

\section{Considerações}

Precisamos recuperar e explorar os aspectos das relações sociais que têm sido suprimidos, desarticulados ou negados dentro de perspectivas dominantes (masculinas). Precisamos recuperar e escrever as histórias de mulheres bem como nossas atividades nos relatos e narrativas que as culturas contam sobre elas mesmas, tendo claro que, assim como os homens, nós interiorizamos as concepções de gênero dominante quanto à masculinidade e à feminilidade, desenvolvendo, desta forma, uma intolerância quanto a diferenças, ambiguidades e conflitos que as experiências de outros e outras nos trazem. Essa recuperação perpassa o espaços formal da educação escolarizada, tornando a sala de aula local privilegiado de inserção das inúmeras questões nas quais está o gênero, hoje presente de modo explícito ou velado nos arranjos curriculares. Neste sentido, os cursos de formação de professores revestem-se de especial importância na quebra de padrões, tradições e mitos inibidores do desapa- recimento dos rígidos papeis determinados pelo sexo e pelo poder patriarcal.

Passadas as dificuldades iniciais dos primeiros contatos com a linguagem adotada, observou-se que houve um impacto junto aos dois alunos da turma que adotaram posturas distintas: um deles participou do debate e defendeu arduamente a prevalência masculina da sociedade como prerrogativa histórica embasada na tradição cultural, mas também alimentada pelas mulheres, ele não respondeu ao questionário; o segundo aluno respondeu monocordicamente às questões abertas e durante os debates tendia a concordar com as conclusões da turma.

A postura dos alunos e alunas demonstra que a sensibilização para o conteúdo gênero ainda tem um percurso a ser trilhado no sentido de vir a também fazer parte da formação de professores e professoras. Contudo, a reação e interação das mulheres assim como as revelações expressas nos depoimentos nos mostram o despertar de uma visão mais crítica das próprias concepções no que diz respeito às relações de gênero, levando-as a compreender os limites historicamente impostos às mulheres, assim como a importância de estabelecer que a criação das identidades apoia-se nas relações sociais entre homens e mulheres nos diversos contextos em que as interações ocorrem. É um processo contínuo, dinâmico de construção e de reconhecimento de si na condição de sujeito participe da construção da história.

\section{Referências}

ABREU, Martha; SOIHET, Rachel e GONTIJO, Rebeca (orgs.). Cultura Política e leituras do passado: historiografia e ensino de história. Rio de Janeiro: Civilização Brasileira, 2007.

BAUMAN, Zygmunt. 0 mal-estar da modernidade. Rio de Janeiro: Jorge Zahar 1998, p.122

BRASIL. Lei no 13.005, de 25 de junho de 2014, que aprova o Plano Nacional de Educação (PNE) e dá outras providências. Disponível em: <http://www.observatorio dopne.org.br/uploa$\mathrm{ds} /$ reference/file/439/documento-referencia.pdf $>$. Acesso em: 05 jun 2017.

COUTO, Maria Aparecida S. Representações de masculinidades e identidades de gênero de estudantes do ensino 
médio e a relação com as violências na escola pública. Tese (Doutorado em Educação). São Cristóvão/SE, 2013. Núcleo de Pós-graduação em Educação. Universidade Federal de Sergipe, 2013.

COSTA, Sueli e SOIHET, Rachel. Ensino de história: conceitos, temáticas e metodologia. Rio de Janeiro: Casa das Palavras: 2009.

CRUZ, Maria Helena Santana. Trabalho, gênero e cidadania: tradição e modernidade. São Cristóvão (SE): Editora UFS; Aracaju: Fundação Oviêdo Teixeira, 2005.

CRUZ, Maria Helena Santana. A crítica feminista à ciência e contribuição à pesquisa nas ciências humanas. Revista Tempos e Espaços em Educação, São Cristóvão (SE), Editora UFS: 2014, v. 7, p. 15-27.

DUBAR, Claude. A construção de si pela atividade de trabaIho: a socialização profissional. Cadernos de Pesquisa. São Paulo, May/Aug. 2012; vol.42; no.146.

GIL, Antônio Carlos. Como elaborar projetos de pesquisa. 4. ed. São Paulo: Atlas, 2002.

HALL, Stuart, A centralidade da cultura: notas sobre as revoluções de nosso tempo. Educação \& Realidade, 1997, v. 22, no 2, p. 15-46.

KARNAL, Leandro (Org.). História na sala de aula: conceitos, práticas e propostas. 6.ed. São Paulo: Contexto, 2015.

LIBÂNEO, José Carlos. Pedagogias e pedagogos, para quê? 12. ed. São Paulo: Cortez, 2010.

LOURO, Guacira; NECKEL, Jane Felipe; GOELLNER, Silvana Vildore (orgs.). Corpo, gênero, sexualidade: um debate contemporâneo. Petrópolis, RJ: Vozes, 2003.

LOURO, Guacira Lopes (org.). 0 corpo educado: pedagogias da sexualidade. 3. ed. Belo Horizonte: Autêntica Editora, 2010.

Millet, Kate. Política sexual. Madrid: Catedra. Traduzido do inglês por Alice Sampaio, Gisela da Conceição e Manuela Torres. Lisboa: Publicações Dom Quixote 1970. Disponível em: <https://repassefeminista.files.wordpress.com/2014/02/k-millet-polc3adtica-sexual.pdf>. Acesso em: 01 jun 2017.

ORGANIZAÇÃO DAS NAÇÕES UNIDAS PARA A EDUCAÇÃO, A ClÊNCIA E A CULTURA (UNESCO). O perfil dos professores brasileiros: o que fazem, o que pensam, o que almejam. São Paulo: Moderna, 2004.

PACHECO, José Augusto. Escritos curriculares. São Paulo: Cortez, 2005.

PINSKY, Carla Bassanezi. Novos temas nas aulas de História. 2. ed. São Paulo: Contexto, 2010.
SCOTT, Joan W. Gênero: uma categoria útil de análise histórica. Educação \& Realidade. Porto Alegre, v. 20, n. 2, p. 71-99, jul./ dez. 1995.

SILVA, Tomaz Tadeu da. Documentos de identidade. Uma introdução às teorias de currículo. 3. ed. São Paulo: Autêntica. 2010.

SILVA, Tomaz Tadeu da; e MOREIRA, Antônio Flávio Barbosa. (orgs.). Territórios contestados: o currículo e os novos mapas culturais e políticos. Petrópolis (RJ): Vozes, 1995.

SANTOS, Boaventura Sousa. Dilemas do nosso tempo: globalização, multiculturalismo, conhecimento. Educação \& Realidade, 2001, v. 26, no 1, p. 13-32.

SANTOS, Boaventura Sousa. Reconhecer para libertar. Rio de Janeiro: Civilização Brasileira, 2003.

Recebido em 13 de maio de 2017.

Aceito em 20 de agosto de 2017. 
